\title{
PROCESSAMENTO DIGITAL DE IMAGENS PARA ESTUDOS DE DINÂMICAS DA PAISAGEM
}

\author{
Digital Image Processing for Landscape Dynamics Studies
}

\section{Procesamiento de Imagen Digital para Estudios Dinámicos de Paisaje}

Felipe Gonçalves Amaral Doutorando do Programa de Pós-Graduação em Geografia da UFRJ

f.g.amaral19@gmail.com

Carla Bernadete Madureira Cruz Professora Titular do Departamento de Geografia da UFRJ carlamad@gmail.com

Camilla Bandeira da Silva Graduanda do Departamento de Geografia da UFRJ camillabandeira22@gmail.com

Paula Maria Moura de Almeida Pós-Doutoranda do Programa de Pós-Graduação em Geografia da UFRJ almeida.pmm@gmail.com

Artigo enviado para publicação em 19/09/2019 e aceito em 04/12/2019

DOI: $10.12957 /$ tamoios.2019.45399

\section{Resumo}

Estudos de dinâmicas da paisagem vem ganhando maior relevância e sendo aplicados a diferentes temas e com diversas metodologias, possibilitando a geração de inúmeras análises espaço-temporais. Com eles urge a necessidade de caracterização, monitoramento e reconhecimento dessas mudanças na paisagem para subsidiar tomadas de decisão. Por isso, cada vez mais a cartografia e as geotecnologias se fortalecem como um dos métodos de diagnósticos, prognósticos e de detecção de mudanças, uma vez que auxiliam as análises quantitativas e qualitativas desses ambientes. Em virtude desta potencialidade, são observados investimentos em diversos métodos de mapeamento e monitoramento das dinâmicas territoriais a partir do Sensoriamento Remoto, métodos esses que apresentam maior complexidade e abrangência, além do avanço em ganho de tempo e precisão. A partir disso esse artigo tem como objetivo a criação de um mapa de mudanças da área que abrange o município do Rio de Janeiro através da detecção de mudanças multitemporais, considerando quatro datas entre 1985 e2015, abordando toda a questão metodológica desse processo, desde o pré-processamento das imagens até o estudo mais específico na classificação integrada das imagens para a realização desse mapa de mudanças, passando pela análise da legenda escolhida e pelo tipo de classificação usado.

Palavras-Chave: Detecção de Mudanças, Mapeamento Multitempotal, Rio de Janeiro, Processamento Digital de Imagens 


\begin{abstract}
With the great need for characterization, monitoring and recognition of landscape changes to support decision making, landscape dynamics studies have been gaining relevance and being applied to different themes and with different methodologies, allowing the generation of countless spatiotemporal analyzes. As a result, cartography and geotechnologies are increasingly becoming stronger as one of the diagnostic, prognostic and change detection methods, as they help the quantitative and qualitative analysis of these environments. Due to this potential, investments are observed in several methods of mapping and monitoring of territorial dynamics from Remote Sensing, which have greater complexity and comprehensiveness, as well as advances in time gain and accuracy. From this this article aims to create a methodology for obtaining a map of changes in the area that covers the municipality of Rio de Janeiro through digital processing of orbital images in a four-date timeframe between 1985 and 2015 , addressing the whole methodological question of this process, from image preprocessing to the more specific study of the choice of spectral dynamic descriptors and hybrid image classification.
\end{abstract}

Keywords: Change Detection, Multitemporal Mapping, Rio de Janeiro, Digital Image Processing

\title{
Resumen
}

Con la gran necesidad de caracterización, monitoreo y reconocimiento de los cambios del paisaje para apoyar la toma de decisiones, los estudios de dinámica del paisaje han ganado relevancia y se han aplicado a diferentes temas y con diferentes metodologías, permitiendo la generación de innumerables análisis espacio-temporales. Como resultado, la cartografía y las geotecnologías son cada vez más fuertes como uno de los métodos de diagnóstico, pronóstico y detección de cambios, ya que ayudan al análisis cuantitativo y cualitativo de estos entornos. Debido a este potencial, se observan inversiones en varios métodos de mapeo y monitoreo de la dinámica territorial de la Teledetección, que tienen una mayor complejidad y exhaustividad, así como avances en la ganancia de tiempo y la precisión. A partir de esto, este artículo tiene como objetivo crear una metodología para obtener un mapa de cambios en el área que cubre el municipio de Río de Janeiro a través del procesamiento digital de imágenes orbitales en un período de cuatro fechas entre 1985 y 2015, abordando toda la cuestión metodológica de este proceso, desde el preprocesamiento de imágenes hasta el estudio más específico de la elección de descriptores dinámicos espectrales y clasificación de imágenes híbridas.

Palabras-clave: Detección de cambios, Mapeo multitemporal, Rio de Janeiro, Procesamiento de imágenes digitales 


\section{Introdução}

Desde o surgimento dos seres humanos, a paisagem é alterada conforme as suas necessidades de expansão, o que torna importante o reconhecimento e a caracterização dessas alterações espaciais, bem como de seus consequentes problemas ambientais. Além disso, o monitoramento dessas mudanças de cobertura se faz essencial, visto que possibilita evitar alterações futuras que podem ser prejudiciais para os ecossistemas, assim como auxilia na proteção e conservação do ambiente.

Estudos de dinâmicas da paisagem vem ganhando maior relevância e sendo aplicados a diferentes temas e com diversas metodologias, possibilitando a geração de inúmeras análises espaço-temporais e dentre esses estudos tem-se a caracterização, o diagnóstico e o monitoramento de áreas de diferentes naturezas (SANTOS, 2004).

Os avanços tecnológicos alcançados e a aparente disseminação da consciência ambiental, entendida como preocupação com a qualidade de vida do homem, intimamente relacionada com a qualidade do meio em que vive, junto com os avanços tecnológicos e novos métodos de representação e monitoramento da paisagem se tornam cada vez mais usuais.

Nesse sentido, os métodos cartográficos conciliados ao desenvolvimento das geotecnologias atuam como uma forma eficaz e precisa de diagnósticos, prognósticos e de detecção de mudanças, tendo em vista que contribuem com análises quantitativas e qualitativas do espaço. Tais análises são realizadas mediante o uso de Sensoriamento Remoto, que tem como grande vantagem o ganho de tempo e precisão no mapeamento, bem como no monitoramento.

A criação de novas metodologias que possam ajudar a controlar, mensurar e qualificar essas dinâmicas, tanto no tempo quanto no espaço, vem sendo cada vez mais necessárias e contribuem metodologicamente para estudos desta natureza, através da aplicação da análise espacial associada ao mapeamento multitemporal (ROSA, 2011; FLORENZANO, 2005).

A partir disso esse artigo tem como objetivo a criação de um mapa de mudanças da área que abrange o município do Rio de Janeiro (Figura 1) através da detecção de mudanças multitemporais, considerando quatro datas entre 1985 e 2015 . Será abordada toda a questão metodológica desse processo, indo desde a questão do préprocessamento das imagens, até o estudo mais específico na classificação integrada das imagens para a realização desse mapa de mudanças, passando pela análise da legenda escolhida e pelo tipo de classificação usado. 


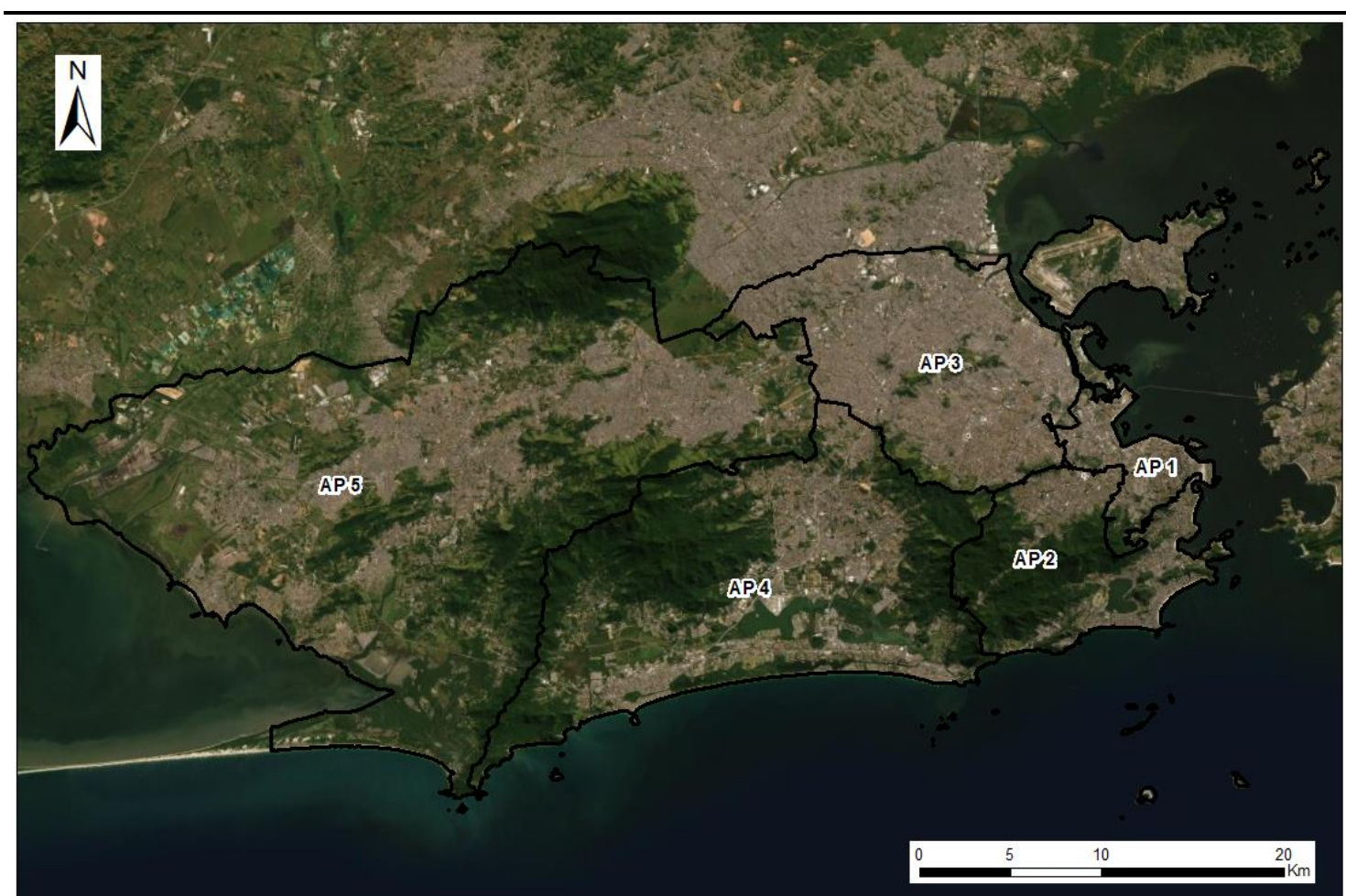

Figura 1 - Área de Estudo e Áreas de Planejamento do Município do Rio de Janeiro

\section{Metodologia}

Um segmento importante do Sensoriamento Remoto é o processamento digital de imagens, que consiste na execução de operações matemáticas dos dados a partir de suas características espaciais e espectrais, visando a geração de produtos sejam apropriados para uma determinada aplicação. $\mathrm{O}$ que significa que o processamento de imagens é orientado para cada tipo de problema. Com ele podemos identificar padrões espaciais e temporais, e localizar e quantificar trajetórias de mudanças geoambientais (MENESES \& ALMEIDA, 2012; NOVO, 2008).

O processamento digital de imagens pode ser dividido em três conjuntos: as técnicas de pré-processamento, cuja aplicação permite transformar dados digitais brutos em dados corrigidos radiométrica e geometricamente; as técnicas de realce, as quais visam melhorar efetivamente a visualização da cena para subsequente interpretação visual ou classificação digital; e técnicas de classificação que têm como finalidade o reconhecimento automático dos objetos da cena, a partir da análise quantitativa dos níveis de cinza (NOVO, 1989).

A decisão de quais técnicas aplicar em cada situação deve ser ditada pelos objetivos a serem alcançados e pelas especificidades da situação de cada projeto. $\mathrm{O}$ uso de dados multitemporais, por exemplo, implica na utilização de métodos mais sofisticados para a retificação radiométrica e geométrica dos dados como serão usados nesse artigo.

No fluxograma abaixo estão apresentados todos os métodos realizados nesse artigo de para que os objetivos fossem alcançados (Figura 2) 


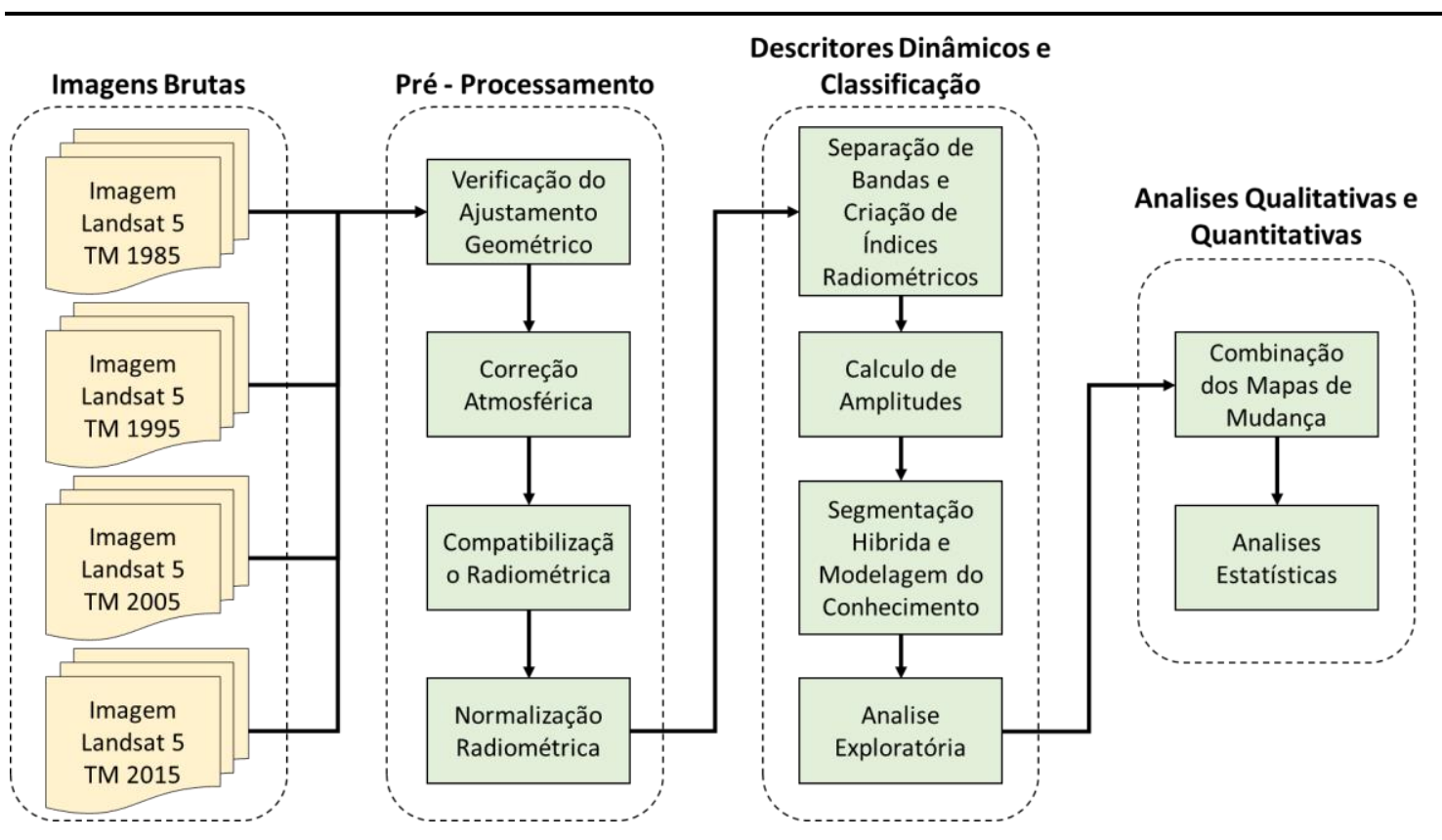

Figura 2 - Fluxograma dos métodos utilizados

\section{Pré-Processamento Digital de Imagens}

Imagens na forma em que são recebidas originalmente dos satélites (denominadas brutas) apresentam degradações radiométricas devido a desajustes na calibração dos detectores, erros esporádicos na transmissão dos dados, influências atmosféricas, e distorções geométricas. Todas estas imperfeições, se não forem corrigidas, podem comprometer os resultados e produtos derivados das imagens.

O pré-processamento, que como vimos anteriormente é a uma etapa do PDI, tem a finalidade então de resolver esses problemas gerais da imagem e facilitar assim o uso dessas para análises posteriores. É uma etapa para que os resultados obtidos de um mapeamento sejam expressivos e confiáveis (MENESES \& ALMEIDA, 2012; NOVO, 2008).

Em estudos de mapeamentos multitemporais integrados erros geométricos e radiométricos podem se multiplicar devido ao recorte temporal, já que são usadas muitas imagens. Dessa forma no âmbito desse trabalho, serão aplicados, antes do uso das imagens para análises visuais ou matemáticas, diversos métodos englobados dentro da categoria de pré-processamento. Dentre os processos estão a validação geométrica (e se preciso o ajuste geométrico entre as imagens) e radiométrico, sendo elas a compatibilidade radiométrica e a normalização radiométrica.

Para esse artigo as imagens escolhidas foram as da série LANDSAT, isso devido seu grande intervalo temporal de imageamento e por ser um satélite com resoluções tanto espaciais quanto espectrais adequadas para classificações de media escala. As imagens foram obtidas através do Catálogo de Imagens do USGS. Essa seleção foi condicionada ao fato de apresentarem menor porcentagem de nuvens, e que tivessem sido coletadas entre os meses de maio a setembro para todos os anos considerados na análise (1985, 1995, 2005 e 2015). Para o pré-processamento foram usadas as bandas espectrais correspondentes entre os sensores TM e OLI, respectivamente presentes no LANDSAT 5 e LANDSAT8.

Com isso, foram descartadas as bandas espectrais novas que aparecem no sensor OLI e as bandas termais dos dois sensores. Em resumo foram utilizadas as bandas do 
Azul, Verde, Vermelho, Infravermelho Próximo e as duas bandas do Infra- Vermelho de Ondas Curtas dos dois sensores.

$\mathrm{Na}$ forma de detecção de mudanças que será abordada nesse artigo, os pixels de cada imagem são comparados um a um, por esse motivo, pequenos erros de registro entre as imagens podem acarretar falsas mudanças, frutos da comparação de pixels que representam locais diferentes da cena e ocasionar uma superestimação das transformações entre as cenas, ou vice-versa (SHALABY, TATEISHI, 2007). É preciso, desta forma, analisar o posicionamento relativo entre o conjunto de imagens usado para o estudo, para detectar a necessidade de se realizar uma correção geométrica em uma ou mais cenas adquiridas.

Para validar geometricamente as imagens, foi considerado que os erros entre o conjunto delas deveriam ser na ordem de subpixel, isso quer dizer que no caso das bandas escolhidas do satélite LANDSAT os erros precisam ser menores do que 30 metros. Assim, o deslocamento não se torna grande o suficiente para os erros de classificação serem consideráveis.

Como estratégia de análise foram coletados 16 pontos correspondentes a mesma posição nas quatro imagens. Esses pontos são distribuídos de acordo com a facilidade de identificação de parâmetros semelhantes no conjunto.

Para o cálculo do erro de posicionamento relativo, é necessário que sejam feitas as extrações das informações de posição $\mathrm{X}$ (Este) e Y(Norte) desse ponto. Como o conjunto de dados possui quatro imagens, obtemos oito campos de informação para cada ponto, quatro para a coordenada Este e quatro para coordenada Norte.

Usando os valores de posicionamento extraídos de cada ponto foi necessário o cálculo das diferenças (erros) entre as coordenadas $\mathrm{X}$ e as coordenadas $\mathrm{Y}$, permitindo achar a resultante dada pela Equação 1 a partir do esquema da Figura 3, que é o erro circular entre as medidas de posição mais extremas entre os pontos.

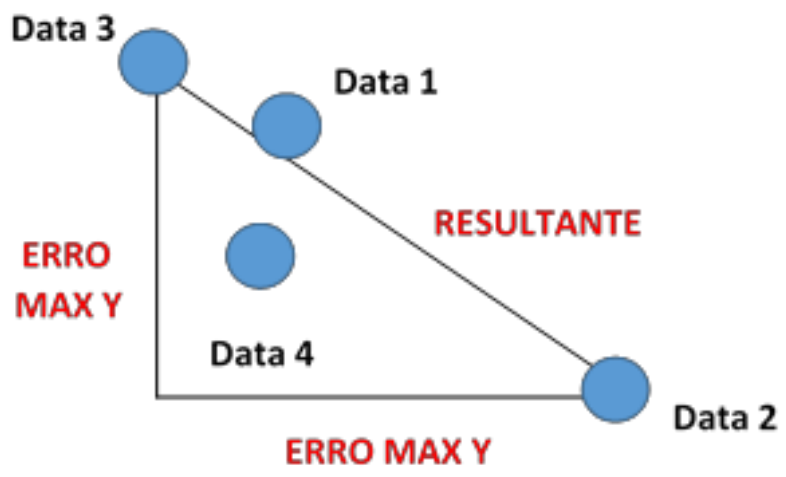

Figura 3 - Cálculo dos Erros e Resultantes dos Pontos

$$
\text { RESULTANTE }=\sqrt{(\text { ERRO MAX X })^{2}+(\text { ERRO MAX Y })^{2}}
$$

\section{Equação 1 - Cálculo do Erro Circular Planimétrico}

Passada a Validação geométrica, passa-se para os problemas geométricos. Quando as imagens na análise de detecção de mudança são de duas ou mais datas, uma pode ter respostas radiométricas de um sensor diferente ao longo do tempo, devido a vários fatores, entre os quais estão: i) diferenças na resposta radiométrica relativa entre os sensores; ii) mudanças na calibração do sensor de satélite ao longo do tempo 
(envelhecimento); iii) diferenças nos ângulos de iluminação e de observação; iv) variação de efeitos atmosféricos; v) refletância; vi) topografia; e, vii) mudanças reais na refletância alvo. (PAOLINI et al, 2006; ESCOBAR, 2015).

A normalização radiométrica de imagens orbitais se torna então uma fase do préprocessamento importante, já tem como objetivo obter um comportamento uniforme no que diz respeito à resposta espectral de alvos considerados invariantes com o tempo (GÜRTLER et al., 2003) devendo ser aplicada antes da realização de análises de monitoramento de índices de radiométricos ao longo do tempo (CANTY et al., 2004).

O processo de normalização radiométrica é uma técnica de calibração relativa que consiste na regressão linear entre imagens multiespectrais em uma série temporal em relação a uma imagem de referência. Esta técnica diminui diferenças radiométricas entre cenas de mesma posição espacial que estão em datas diferentes (YUAN e ELVIDGE, 1996; YANG e LO, 2000).

Para a realização desse método são selecionados PIFs (Pontos PseudoInvariantes), ou seja, pixels cuja resposta espectral variou pouco ou se manteve constante em todas as imagens da série multitemporal (DU, et al. 2002 apud MALUF et al.,2015).

Como as imagens foram adquiridas pela USGS já corrigidas atmosfericamente, logo estão em valores físicos escalonados de 0 a 10.000 nessa área de estudo, dessa forma foi necessário realizar um reescalonamento radiométrico ou uma compatibilidade radiométrica. A compatibilidade radiométrica tem como principal objetivo a transformação dos valores físicos encontrados na correção atmosférica em valores inteiros positivos que possam ser válidos para a realização da normalização radiométrica. Para isso decidiu-se fazer uma transformação simples.

Os valores físicos advindos da correção atmosférica da USGS foram valores entre 0 a 10.000, sem casas decimais, como resposta espectral em uma certa banda. $\mathrm{O}$ método usado para converter esse valor para um número inteiro foi multiplica-lo por 100 usando a ferramenta Raster calculator do ArcMap 10.3, com isso salvando os valores, a partir daí temos agora a possibilidade de encontrarmos na imagem valores entre 0 e 1000000. Com isso valores inteiros que são bem representativos em relação aos valores originais. Por fim, a necessidade de transformar esses valores que se encontram em 32 bits, radiometria padrão dos resultados do software PCI Geomatica, para imagens de 16 bits usando a ferramenta Copy Raster do ArcMap 10.3 e assim reescalonando a imagem para valores entre 0 e 65.535 .

Feita a compatibilidade e agora com valores inteiros positivos, passou-se a normalização radiométrica. Para realizar a normalização, a primeira medida é a seleção dos PIFs, para esse artigo foram selecionados 300 PIFs, entre eles presentes pixels claros e escuros e tentando abarcar todas as pluralidades apresentadas na cena (Figura 4). Esses PIFs foram selecionados a partir de análise visual de invariância de resposta radiométrica, no programa ArcMap 10.3.

O software escolhido para fazer a regressão linear das imagens a partir de uma imagem de referência e dos PIFs foi o software R, um software estatístico que possui entre suas funções ferramentas externas como o raster e o rgdal que tem como premissa o trabalho com imagens de diferentes origens, através de um código desenvolvido por FERNANDES et al. (2017).

Além dos PIFs, foi necessário a escolha de uma imagem de referência, que a partir dela seria feito a regressão, trazendo as outras imagens para sua realidade radiométrica. A imagem de 2005 foi usada como referência, e a partir dessa foram geradas três imagens normalizadas, as de 1985, 1995 e 2015. 


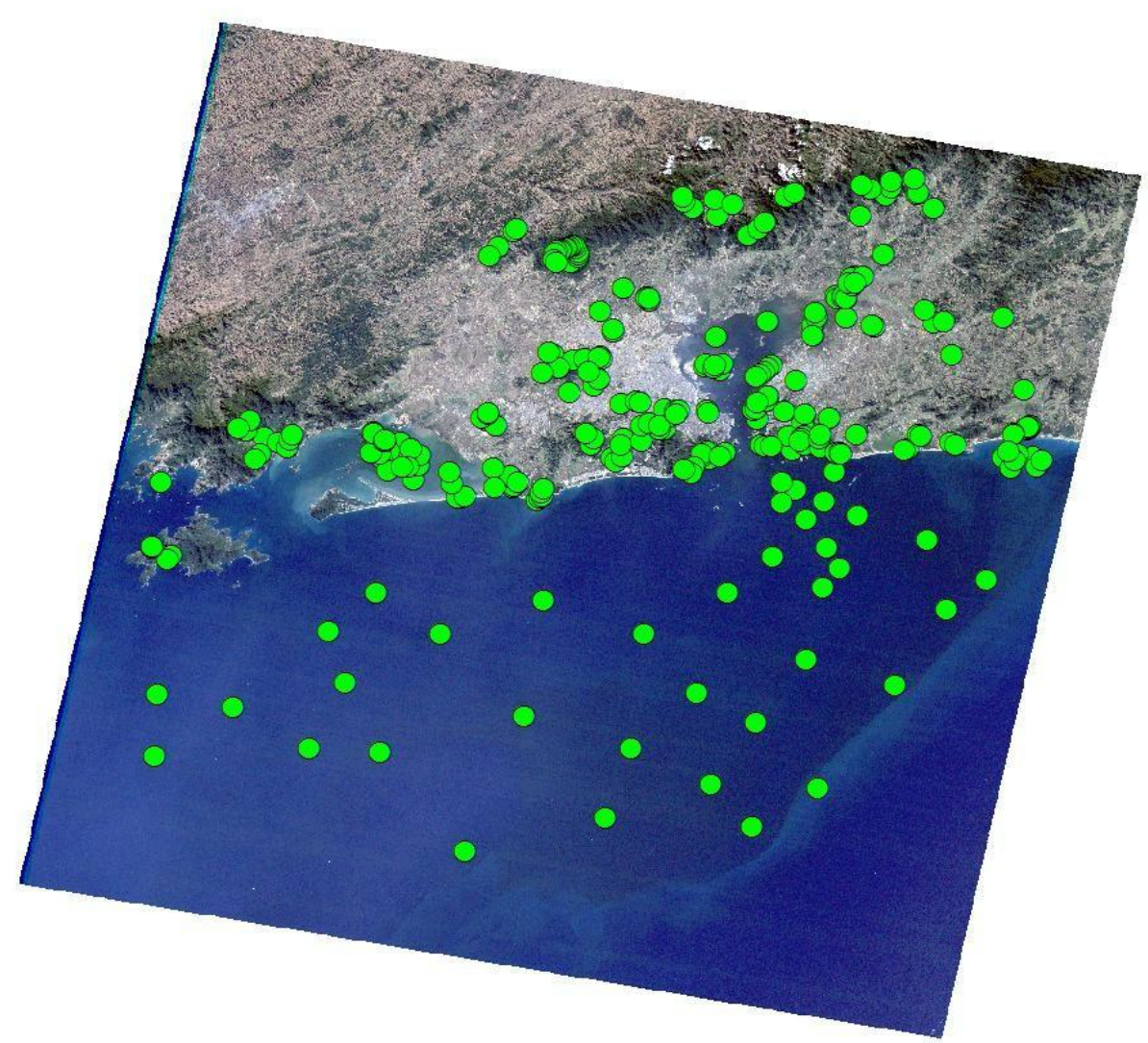

Figura 4 - Distribuição dos PIFs para a Normalização

\section{Descritores Dinâmicos e Classificação}

Com as imagens devidamente processadas em termos de correções geométricas, atmosféricas e radiométricas, utilizou-se a técnica de classificação hibrida, essa caracterizada por possuir atributos ligados ao pixel e atributos ligados a objetos geográficos (GEOBIA) (VICENS et al, 2016).

A criação de uma legenda dinâmica é o primeiro passo do método empregado. A legenda escolhida foi simples, focando na diferenciação de áreas que apresentavam mudança e não mudança. Definiu-se que dinâmicas mais intensas no uso do solo seriam mapeadas como mudança e dinâmicas menores ou sutis, assim como a não alteração, seriam mapeadas como não mudança. Logo somente mudanças abruptas na paisagem serão classificadas por esse método. A partir daí para o mapeamento, como a classificação e a segmentação serão feitas de forma híbrida, os atributos ligados ao pixel foram criados no ArcMap 10.3, fora do Ecognition Developer 9.1, que foi o software escolhido para a realização da classificação.

O método usado para investigar a dinâmica da paisagem foi a amplitude que é uma medida de dispersão que nos dá a diferença entre o maior valor e o menor valor entre o conjunto, já que para fins de descritores dinâmicos, a subtração de imagens é uma operação de grande recurso prático. Nas imagens essa amplitude será calculada de pixel a pixel a partir da álgebra de matrizes, entre as quatro datas de estudo, e as diferenças entre os maiores e menores valores serão descritas numa nova imagem.

Foram criadas imagens de amplitude para as bandas espectrais do vermelho (Figura 5), e do infravermelho próximo (Figura 6) e para os índices radiométricos NDVI (Figura 7) e NDBI (Figura 8). 


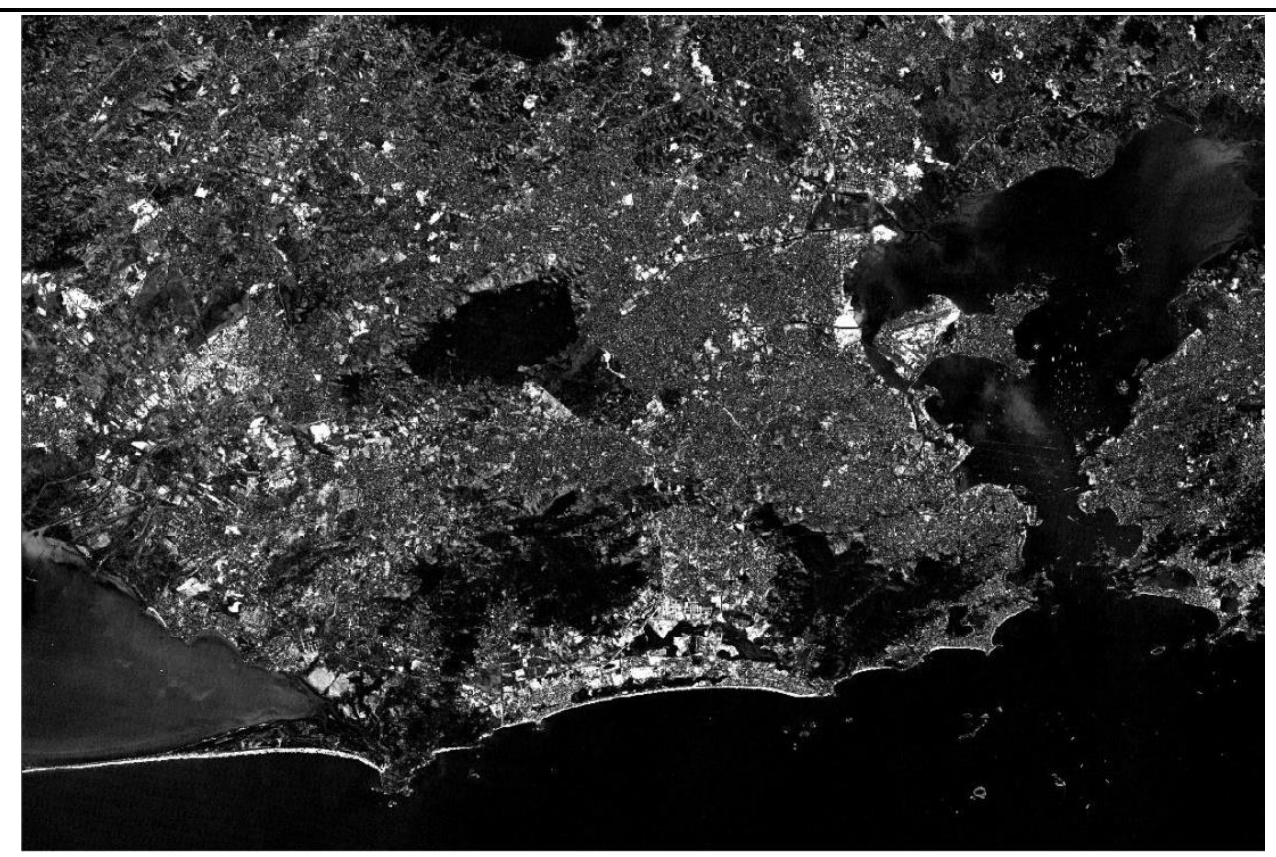

Figura 5 - Imagem de Amplitude do Vermelho

Nas quatro imagens de amplitude, os valores escuros ou mais baixos são interpretados como áreas de não mudança, pois possuem valores muito próximos de 0 , e os valores mais claros são as áreas de mudança, de acordo com o descritor. Podemos ver que alguns descritores deixam mais claro que outros as áreas de mudança, e isso já pode ser assimilado para a criação de modelos para a classificação posteriormente.

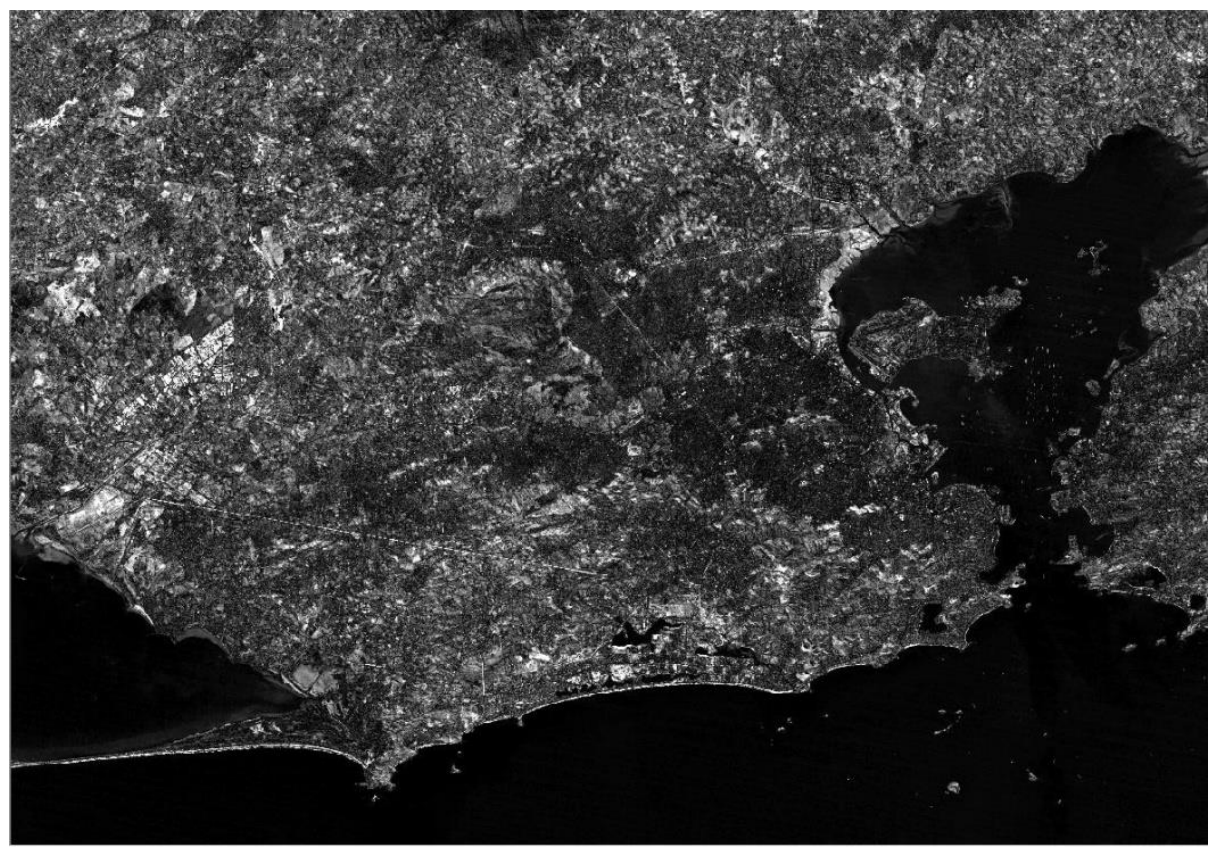

Figura 6 - Imagem de Amplitude do Infravermelho

Essas imagens de amplitude, junto com todas as bandas espectrais de cada ano e o SRTM da área serão nossa matéria prima para a classificação integrada e a criação de um mapa dinâmico e da análise exploratória dos descritores. Esse conjunto de dados será inserido no software Ecognition Developer 9.1 e processado em forma de classificações de imagens. 


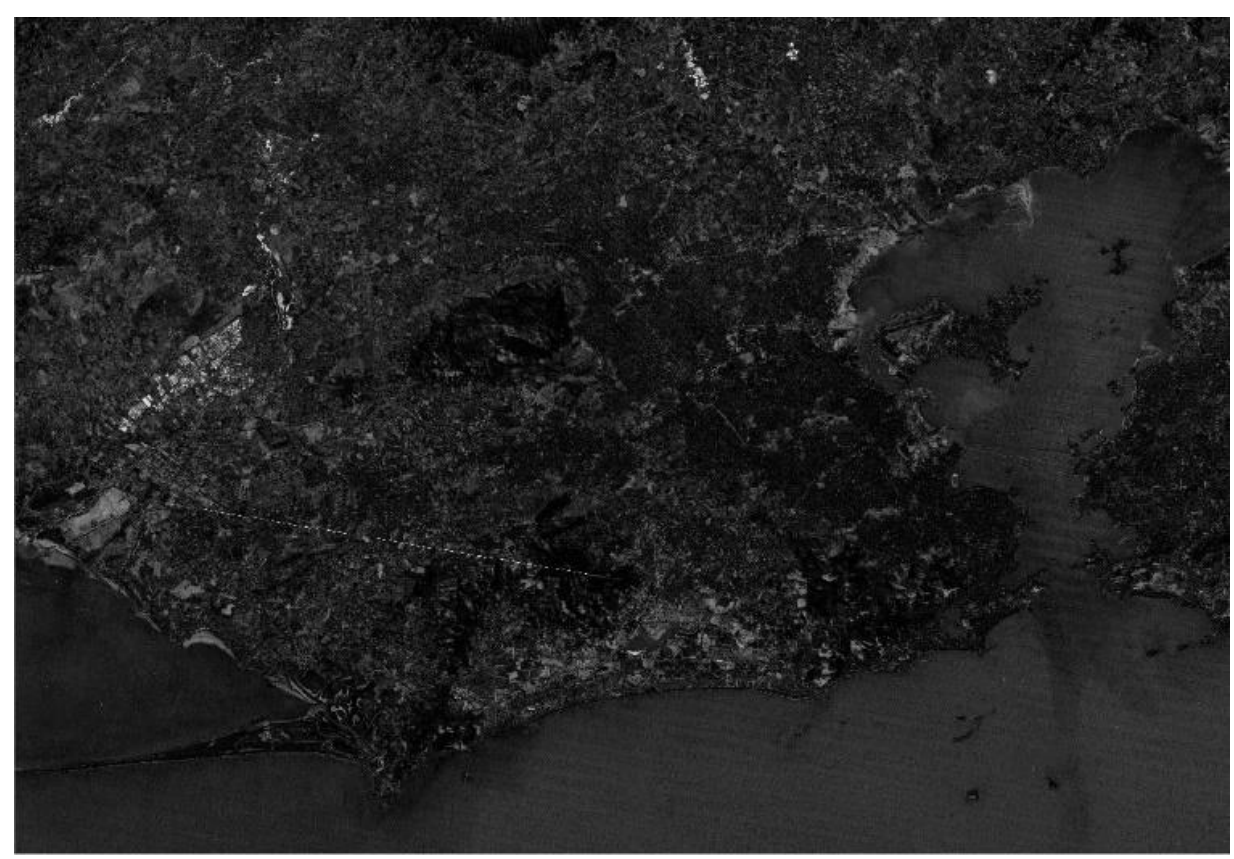

Figura 7 - Imagem de Amplitude do NDVI

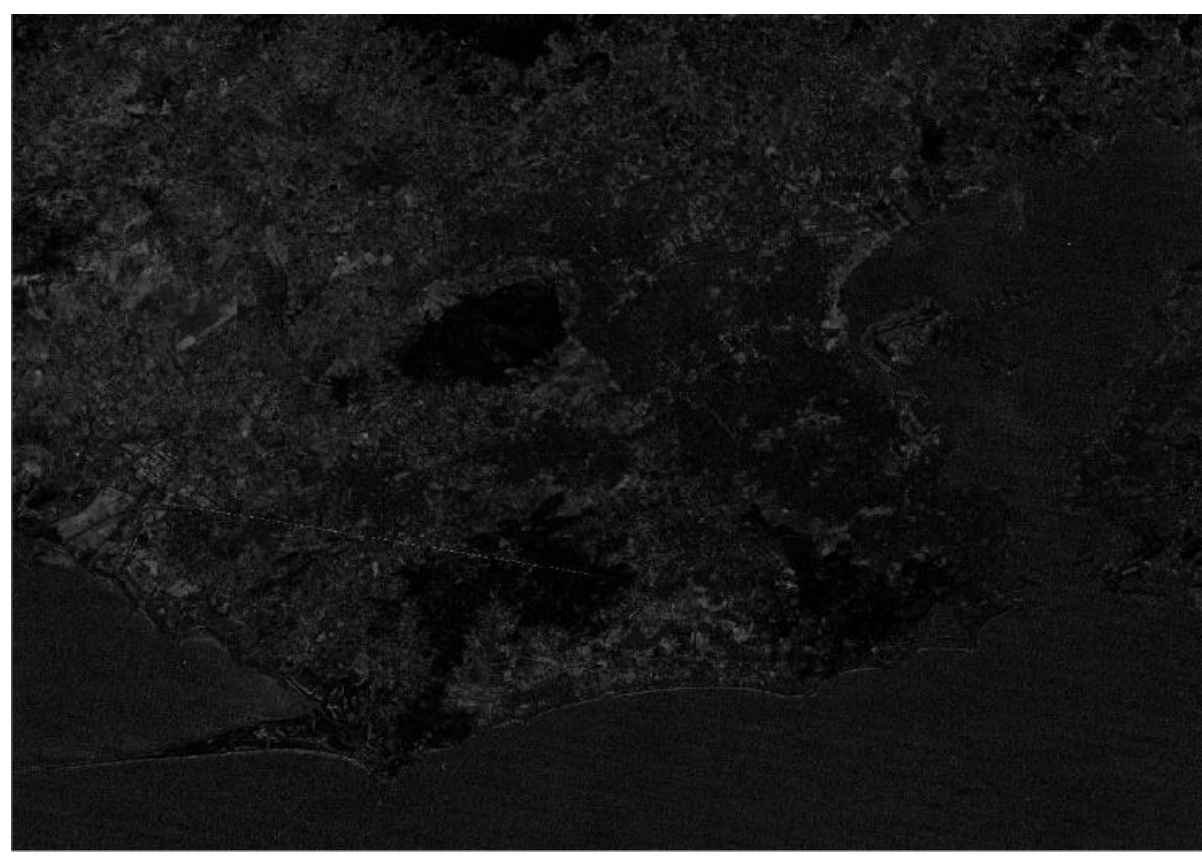

Figura 8 - Imagem de Amplitude do NDBI

Para a realização da classificação das imagens utilizadas será adotada a técnica de classificação baseada em objetos geográficos, GEOBIA (Geographic Object Based Image Analysis ou Análise de Imagem Orientada a Objeto) como já mencionado anteriormente. O que diferencia essa metodologia é a forma de segmentação da imagem, que divide a imagem em segmentos ou objetos, que são separados usando critérios de homogeneidade em uma ou mais direções. Dessa forma o objeto recebe informações espectrais adicionais, como valores de média por banda, máximo e mínimo, desvio padrão, entre outros. Com isso as análises espectrais são todas feitas a partir desse objeto criado pela segmentação semântica.

Para a simplificação da segmentação, foi feita uma hierarquia de classes que 
num primeiro momento separa Água da Área continental. Essa primeira parte da classificação foi feita a partir da modelagem do descritor NDWI, um índice próprio para analises de áreas aquáticas, foram usados os descritores de 2005 e de 1985, e a partir daí criou-se um modelo, onde é necessário que nas datas de 1985 o descritor aponte a presença de água e na de 2015 também. O descritor usado foi o NDWI, criado a partir da diferença normalizada as bandas do verde e do infravermelho próximo, usando o limiar boleado de maior que 0,1 . Dessa forma pode-se ter certeza que a área classificada se manteve todo o período de estudo. Usando essa condição foram classificadas as áreas consideradas como água na série temporal como um todo, e todas as outras áreas foram classificadas como Áreas Continentais.

Após a classificação dos corpos hídricos foram feitas diversas modelagens dentro das áreas continentais, para definir áreas de mudança e não mudança. Foram usadas as quatros amplitudes já herdadas pelos objetos, consideradas aqui já um descritor dinâmico. Para cada descritor foram escolhidos seis limiares para modelar a classe não mudança. Esses limiares foram escolhidos a partir de uma análise simples, como os descritores usados são as amplitudes, os valores próximos de 0 são as áreas de não mudança e os valores cada vez mais distantes dos zeros, são mudanças radiométricas maiores, isso quer dizer mudanças maiores na paisagem, nos limiares para as amplitudes dos índices radiométricos NDVI e NDBI as áreas de não mudança, além de envolver resultados próximos do valor mínimo, o 0 , também abarcam valores próximos do valor máximo igual a 2.

Usando os descritores diferentes limiares dos descritores mencionados acima para a modelagem do conhecimento, foram criados diversos modelos totalizando 24 classificações. Uma análise exploratória manual a partir de pontos de validação foi realizada sob esses descritores e limiares a partir das classificações para buscar o melhor descritor e mais que isso fazer a análise dos descritores e limiares escolhidos, para conseguirmos entender como cada um deles funciona na classificação. A partir das 24 classificações temáticas com a legenda de água, mudança e não mudança, foram criados 500 pontos aleatórios de validação onde foram feitas as análises dos resultados (Figura 9).

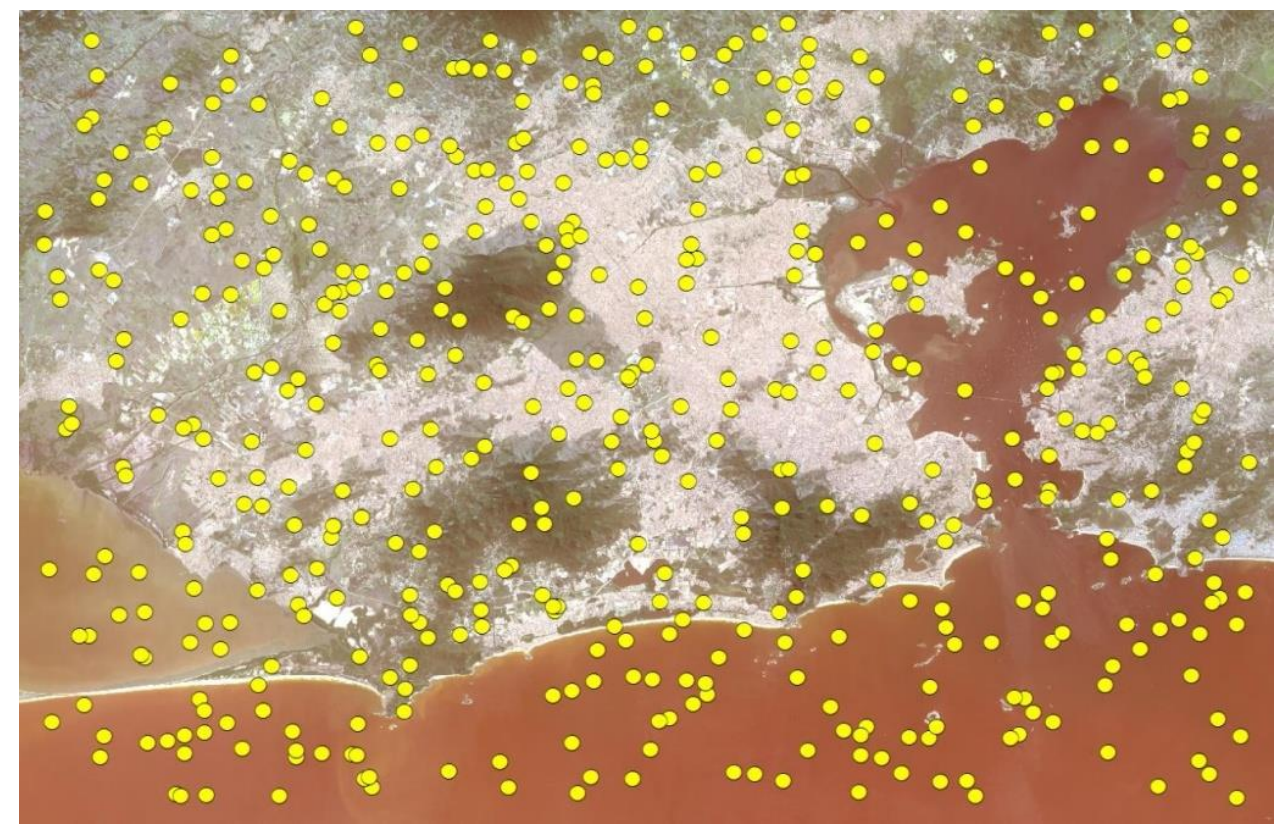

Figura 9 - Distribuição dos Pontos para a análise das classificações 
A partir desses pontos foram geradas tabelas de erros e acertos para o cálculo da acurácia de cada descritor e de cada limiar ligado a descritor. No fim com o melhor descritor e seu melhor limiar foi gerado o mapa de mudança do uso do solo que representa as mudanças que ocorreram durante todos os períodos.

Para entendermos temporalmente a dinâmica da paisagem do município foi necessário a criação dos mapas de mudanças por períodos, esses mapas foram feitos a partir das diferenças do melhor descritor entre os períodos escolhidos usando a mesma modelagem usada anteriormente, mas ao invés de uma modelagem para amplitudes, foram feitas modelagens para a diferença para cada período estudado.

A partir dos mapas de mudanças de cada ano temos uma quantidade de informação para fazer uma análise espaço-temporal completa, para isso o método usado é a álgebra de mapas. O método de Álgebra de Mapas usado foi o Combine. A ferramenta combine considera vários arquivos matriciais de entrada e atribui um novo valor para cada combinação única de valores de entrada no arquivo matricial de saída (é importante, preliminarmente, uniformizar nomes de arquivos e variáveis). Os valores das células originais de cada uma das entradas são gravados na tabela de atributos do raster de saída. Os itens adicionais são adicionados à tabela de atributo do raster de saída, uma para cada raster de entrada (Figura 10).
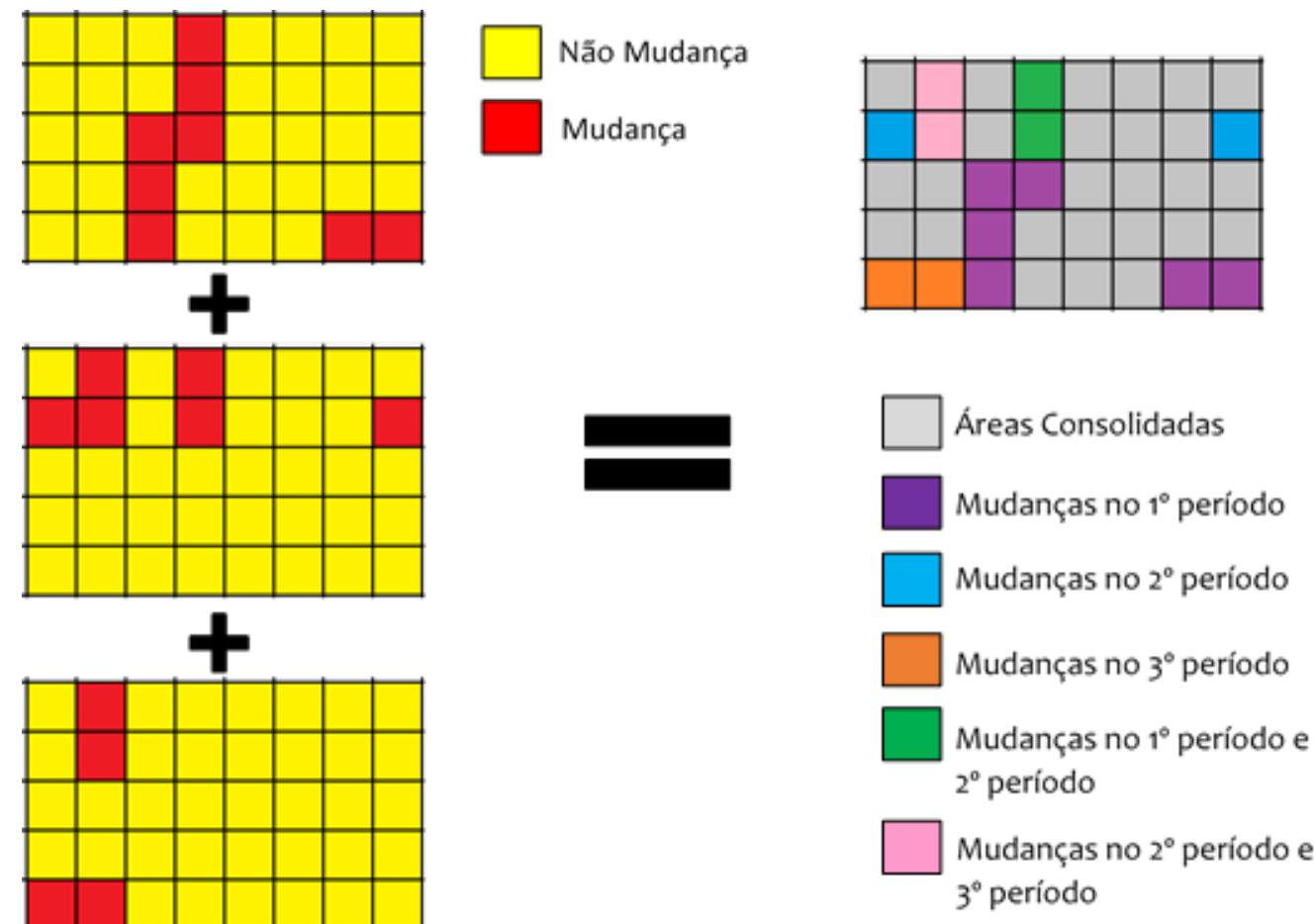

Figura 10 - Método do Combine

\section{Resultados}

Os resultados encontrados podem ser divididos nos geométricos e nos radiométricos para a fase do pré-processamento. No caso da geometria temos que todos os 16 pontos coletados pela imagem tiveram deslocamento entre as imagens abaixo de 30 metros, logo todos os erros planimétricos da imagem relativos as outras datas são consideradas subpixel (Tabela 1 e 2). 


\begin{tabular}{|c|c|c|c|c|c|c|c|}
\hline PONTO & MAX X & MIN X & ERRO X & MAX Y & MIN Y & ERRO Y & RESULTANTE \\
\hline P1 & 682961,2 & 682945,4 & 15,77581 & 7478388 & 7478368 & 20,09184 & 25,54522089 \\
\hline P2 & 665544,7 & 665528 & 16,66878 & 7469308 & 7469294 & 13,49377 & 21,44598304 \\
\hline P3 & 690945,1 & 690929,8 & 15,34586 & 7470265 & 7470247 & 18,05785 & 23,69771063 \\
\hline P4 & 682136,7 & 682123,5 & 13,22919 & 7458020 & 7457994 & 25,70697 & 28,91124096 \\
\hline P5 & 619771,1 & 619768,5 & 2,645839 & 7463050 & 7463033 & 16,93337 & 17,1388297 \\
\hline P6 & 678735,2 & 678725,7 & 9,525019 & 7476270 & 7476264 & 6,35001 & 11,44764666 \\
\hline P7 & 680751,5 & 680742 & 9,52502 & 7474316 & 7474308 & 8,46668 & 12,74404474 \\
\hline P8 & 631905,8 & 631904,4 & 1,322919 & 7464594 & 7464594 & 0 & 1,322918999 \\
\hline P9 & 638217,4 & 638205,8 & 11,64169 & 7475289 & 7475276 & 13,75836 & 18,02280267 \\
\hline P10 & 688124,5 & 688121,9 & 2,645838 & 7466732 & 7466724 & 7,40835 & 7,866645311 \\
\hline P11 & 638117,6 & 638115,2 & 2,381255 & 7473805 & 7473800 & 5,0271 & 5,562563248 \\
\hline P12 & 708931,3 & 708929,2 & 2,116671 & 7459809 & 7459807 & 2,11668 & 2,993431199 \\
\hline P13 & 702137 & 702132,7 & 4,233342 & 7498075 & 7498072 & 3,175 & 5,291673607 \\
\hline P14 & 761296,9 & 761284,2 & 12,70002 & 7503385 & 7503379 & 6,35001 & 14,19905849 \\
\hline P15 & 749998,2 & 749985,5 & 12,70003 & 7478300 & 7478278 & 21,16671 & 24,68441355 \\
\hline P16 & 750107 & 750103,8 & 3,175006 & 7488147 & 7488123 & 23,81254 & 24,02327463 \\
\hline
\end{tabular}

Tabela 1 - Resultado dos Erros do Ajuste Geométrico

\begin{tabular}{|c|r|}
\hline PONTO & RESULTANT \\
\hline P8 & 1,322918999 \\
\hline P12 & 2,993431199 \\
\hline P13 & 5,291673607 \\
\hline P11 & 5,562563248 \\
\hline P10 & 7,866645311 \\
\hline P6 & 11,44764666 \\
\hline P7 & 12,74404474 \\
\hline P14 & 14,19905849 \\
\hline P5 & 17,1388297 \\
\hline P9 & 18,02280267 \\
\hline P2 & 21,44598304 \\
\hline P3 & 23,69771063 \\
\hline P16 & 24,02327463 \\
\hline P15 & 24,68441355 \\
\hline P1 & 25,54522089 \\
\hline P4 & 28,91124096 \\
\hline
\end{tabular}

Tabela 2 - Resultado dos Erros do Ajuste Geométrico

Com esses resultados, não foi necessário fazer qualquer outra correção geométrica nas imagens para a realização de estudos multitemporais integrados.

Nos ajustes radiométricos da imagem, passamos por duas fases, a necessidade da realização de compatibilidades radiométricas e para a realização da normalização radiométrica.

E por fim a validação da normalização radiométrica que pode ser vista nas Figuras 11, 12 e 13 mostram que nos pontos invariáveis as curvas se mantiveram bem 
próximas isso nos dá uma confiança nas análises futuras.

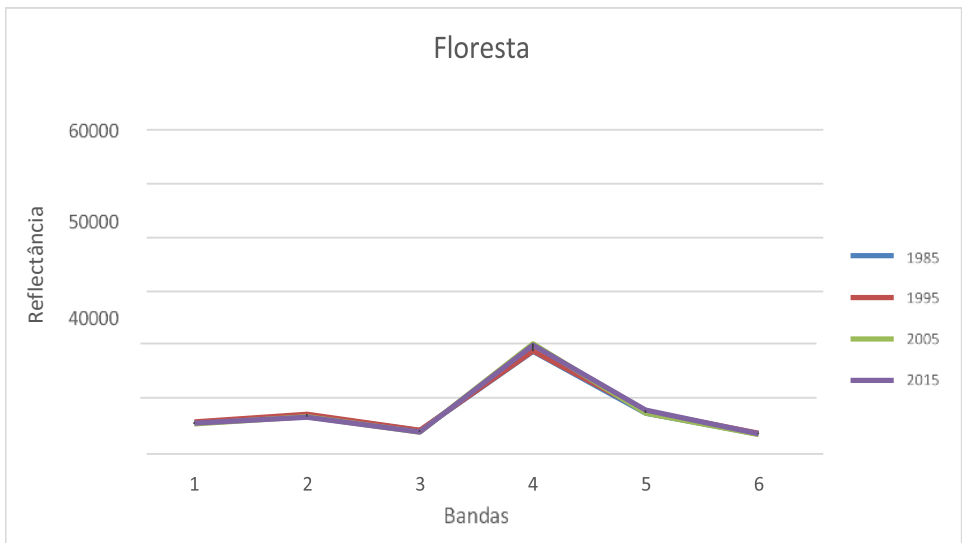

Figura 11 - Curva Espectral pós Normalização das Amostras de Floresta

Tanto nas amostras de floresta como nas de urbano e de água, as curvas nos pontos invariantes se mantiveram muito semelhantes, que é a função da normalização radiométrica, trazer as curvas para a base de referência usando os pontos pseudoinvariantes. Esse resultado nos dá segurança para as análises posteriores a partir dos descritores feitos de diferenças entre imagens de períodos diferentes. Mas podemos observar que as curvas referentes à classe da cobertura urbana são as que possuem uma discrepância maior, pois cada área urbana pode ter uma característica radiométrica diferente, levando isso em consideração os resultados foram bastante relevantes.

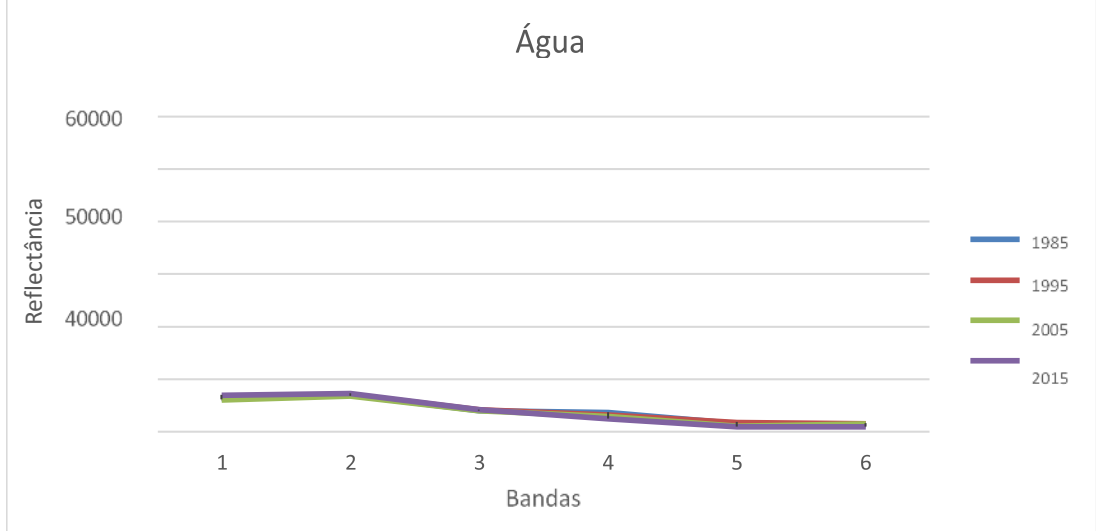

Figura 12 - Curva Espectral pós Normalização das Amostras de Água 


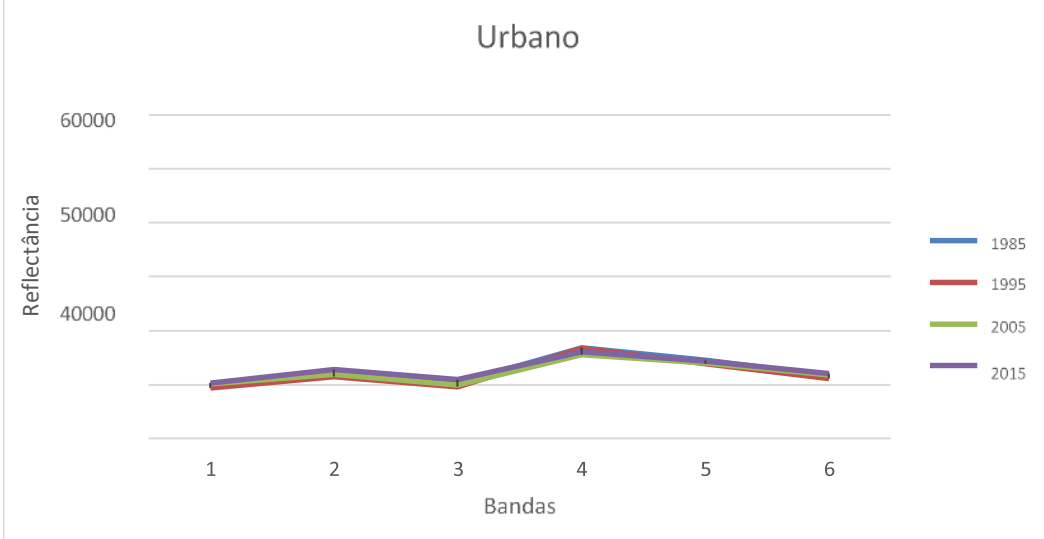

Figura 13- Curva Espectral pós Normalização das Amostras de Urbano

Para a análise dos resultados da segunda etapa da metodologia do artigo dividimos entre as amplitudes dos índices radiométricos e das bandas espectrais. Em relação aos índices radiométricos, que podem ser vistos na Figura 14, os limiares próximos a 0,4 foram os que obtiveram mais acertos, chegando próximos de $80 \%$, que é um resultado muito bom considerando a quantidade de pontos usados para a validação.

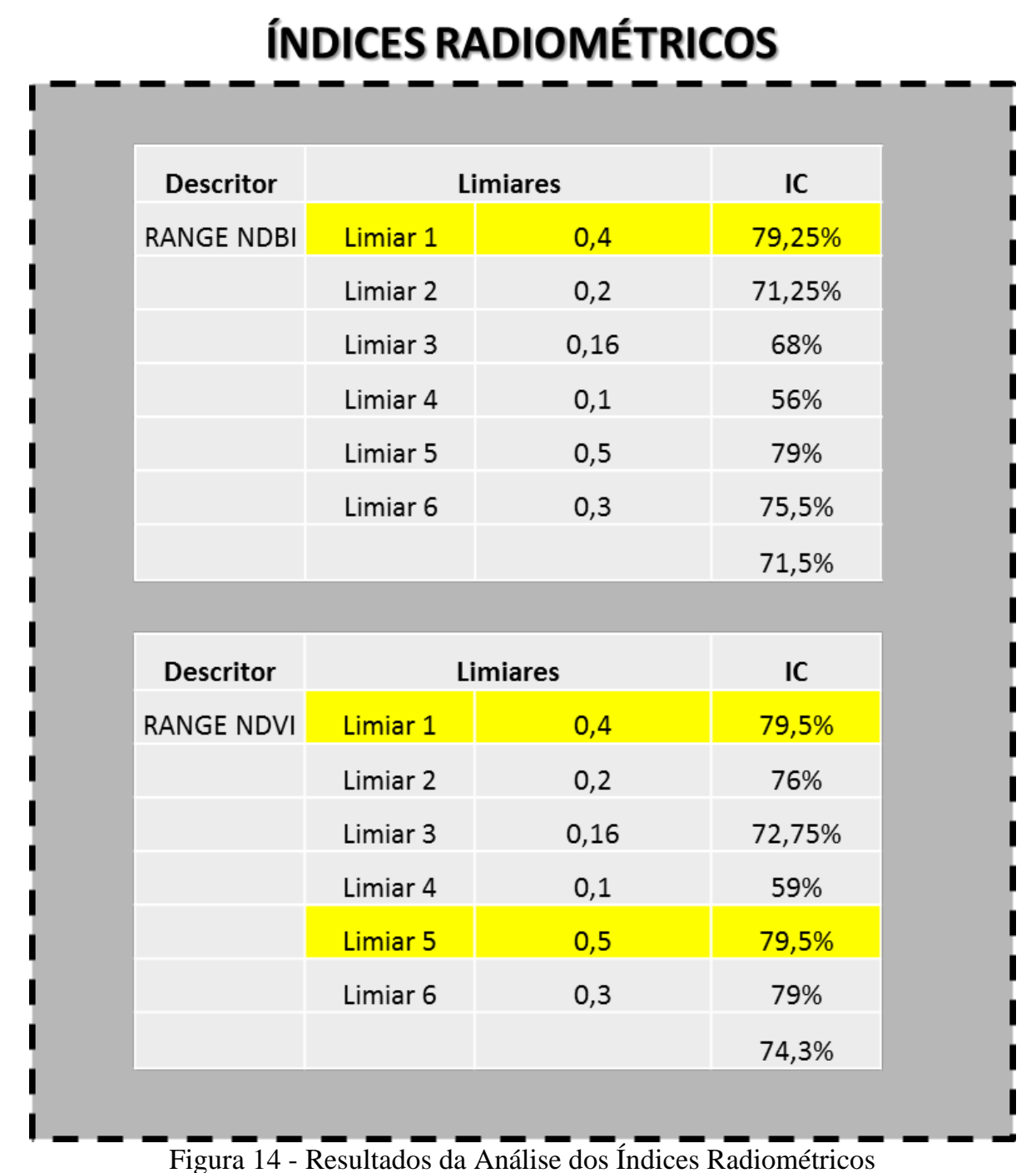


Os limiares muito próximos do 0 , como o 0,1 e o 0,16 foram os que nos deram a menor porcentagem de acertos, logo os piores resultados. Em relação ao descritor, vemos que tanto o NDVI, quanto o NDBI tiveram porcentagens altas levando em conta a média de todos os limiares.

Já nos descritores que envolvem as amplitudes de bandas espectrais tivemos resultados totalmente opostos e surpreendentes (Figura 15). A amplitude do infravermelho próximo não foi um bom descritor, somente um limiar chegou próximo ao $70 \%$ de acerto, e foi o mais próximo do 0 , seu resultado da média global foi de $58,7 \%$, um pouco mais da metade dos pontos, considerando que esses pontos de validação possuíam água também, esse resultado é muito ruim. Já a amplitude da banda do vermelho apresentou resultados surpreendentes, com todos os limiares ficando muito próximos a $80 \%$, o que é considerado um resultado muito bom.

$\mathrm{O}$ segundo limiar do descritor amplitude das bandas do vermelho, das quatro datas em estudo, foi a que nos deu melhor resultado segundo a análise exploratória, e a partir disso esse descritor, com o limiar de 3596 foi usando como classificador final do mapeamento de mudança, já que seu índice de acerto foi de $82,75 \%$, dessa forma esse será o valor de exatidão temática do mapa.

BANDAS ESPECTRAIS

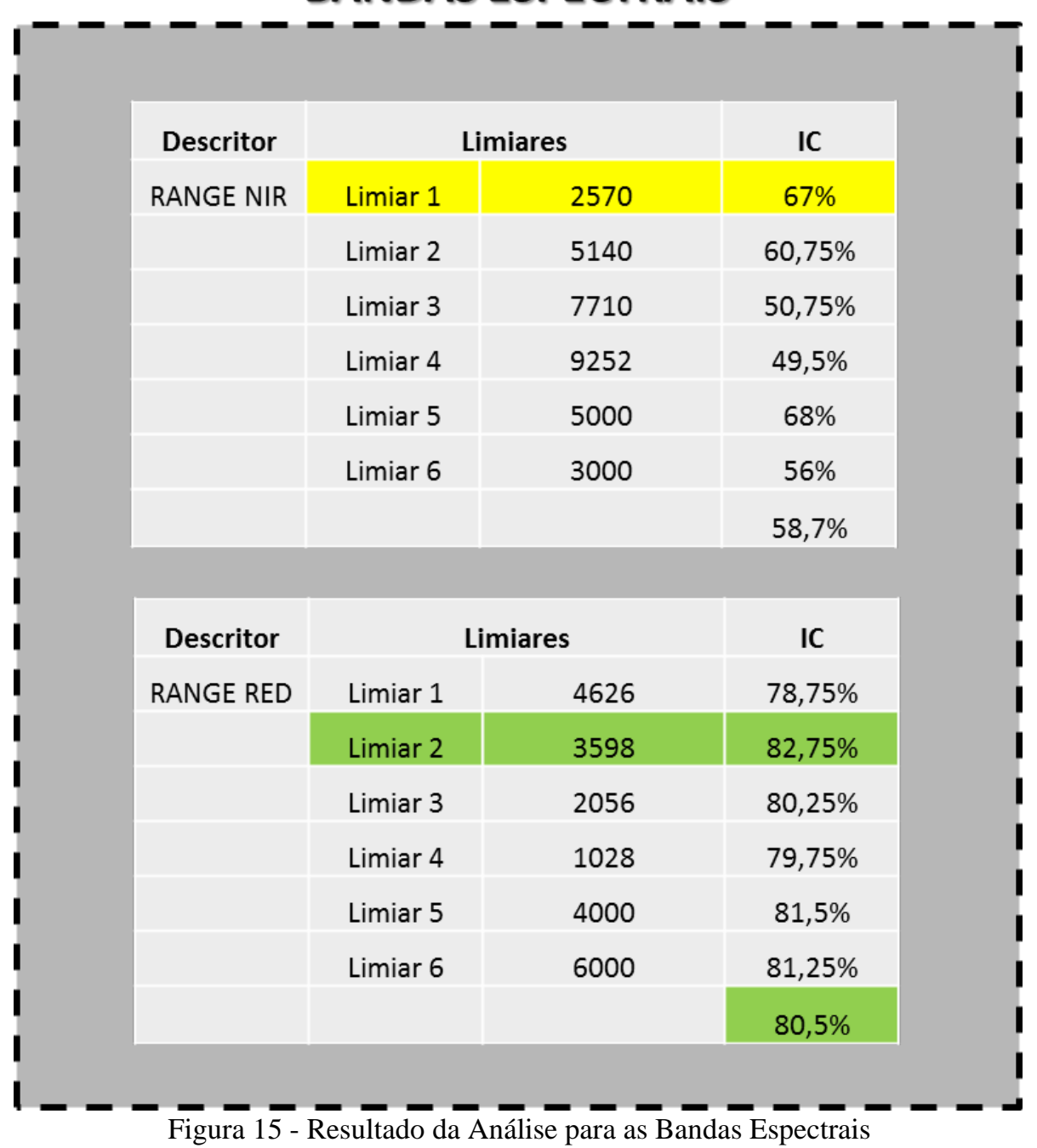

A partir do mapa (Figura 16) podemos perceber que as Áreas de Planejamento 4 e 5 do município do Rio de Janeiro e as áreas mais periféricas e de expansão da mancha 
urbana na baixada fluminense foram as áreas mais dinâmicas. Outra observação que faz-se a partir do mapa é o quanto a mancha urbana do município e suas áreas ao entorno são consolidadas e que como a metodologia foi criada para a detecções abruptas, pequenas modificações na área urbana não foram detectadas, isso também vêm devido de um que possui pixels de $900 \mathrm{~m}^{2}$, o que dificulta a identificação de áreas muito pequenas sem ser consideradas ruídos.

A percepção da dinâmica também deixa bem claro que o descritor usado para o mapeamento identifica muito bem mudanças na área urbana, uma característica muito importante a ser destacada, mas que não detecta com facilidade outros tipos de mudanças como em áreas verdes, sejam elas agropastoris, sejam elas florestadas.

Levando em consideração o mapa de podemos perceber que as Áreas de Planejamento 4 e 5, mais conhecidas como Zona Oeste são as que mais possuíram dinâmica. Essas dinâmicas podem ser explicadas por diversos motivos. O primeiro é a consolidação das outras áreas, como a Zona Sul e Central do município possuem poucas áreas de mudança.

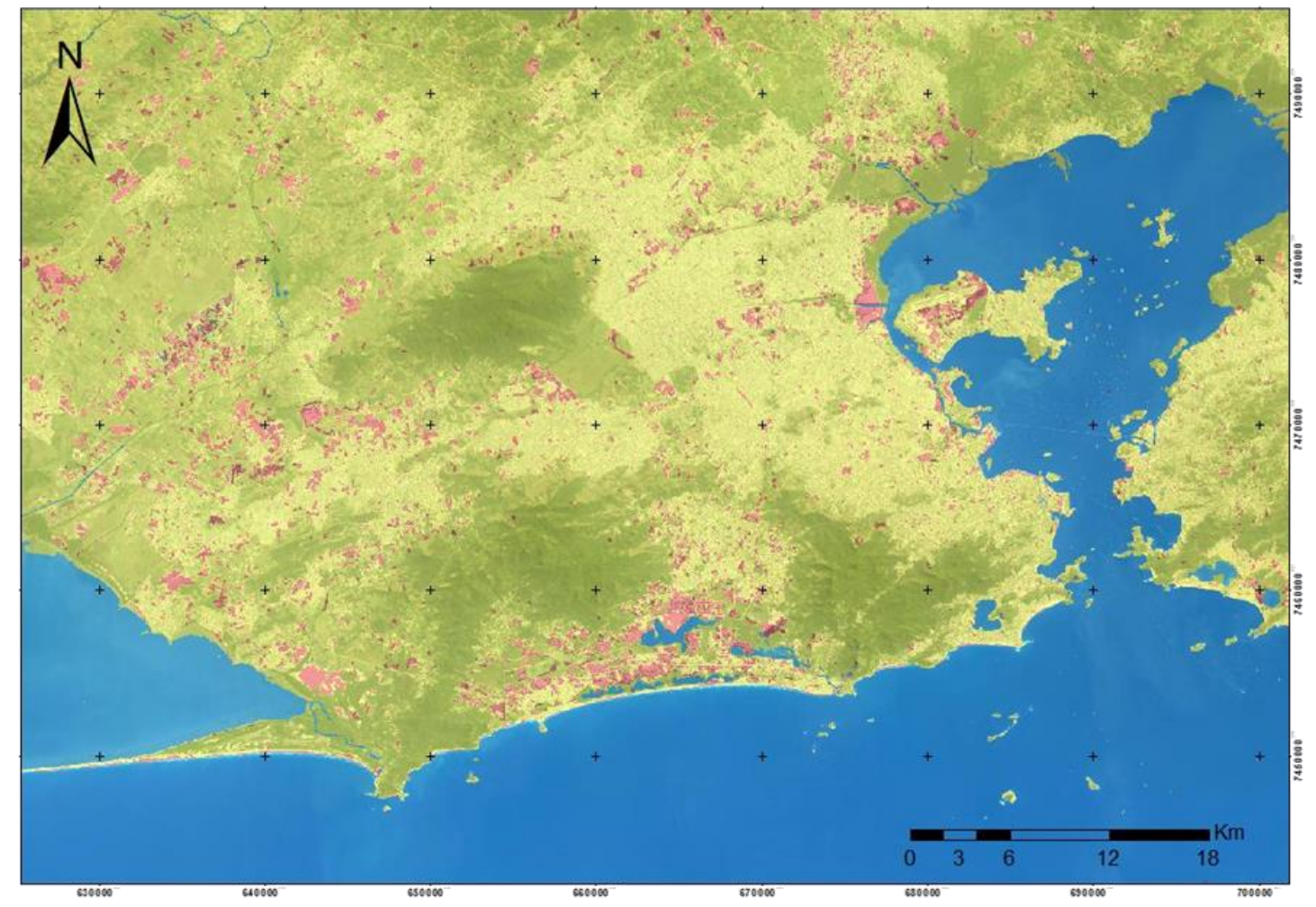

Mudanças e Não Mudanças na área de estudo entre 1985 a 2015, usando o Limiar RANGE VERMELHO, com o limiar de 3598.

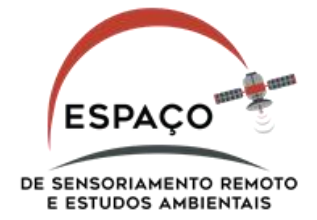

Elaboração:

AMARAL, F. G.;

CRUZ, C. B. M., 2017

Figura 16 - Mapeamento de Mudança
Não Mudança

Mudança

Água

Já a partir do Combine dos mapas de mudança por períodos feito pelas 
diferenças da banda do VERMELHO que como mostrado acima foi o melhor descritor, foi possível analisar a temporalidade das mudanças e a espacialização dessa temporalidade. Dessa forma o mapa apresentado na Figura 20 nos dá a possibilidade de entender a dinâmica total das mudanças, agora com o recorte específico no município do Rio de Janeiro, no espaço e no tempo.

Ainda a partir desse mapa criou-se estatísticas que nos dão a dimensão quantitativa dessas mudanças de forma espacial e temporal divididas a partir do recorte espacial das Áreas de Planejamento (APs) do município. (Tabelas 3 e 4).

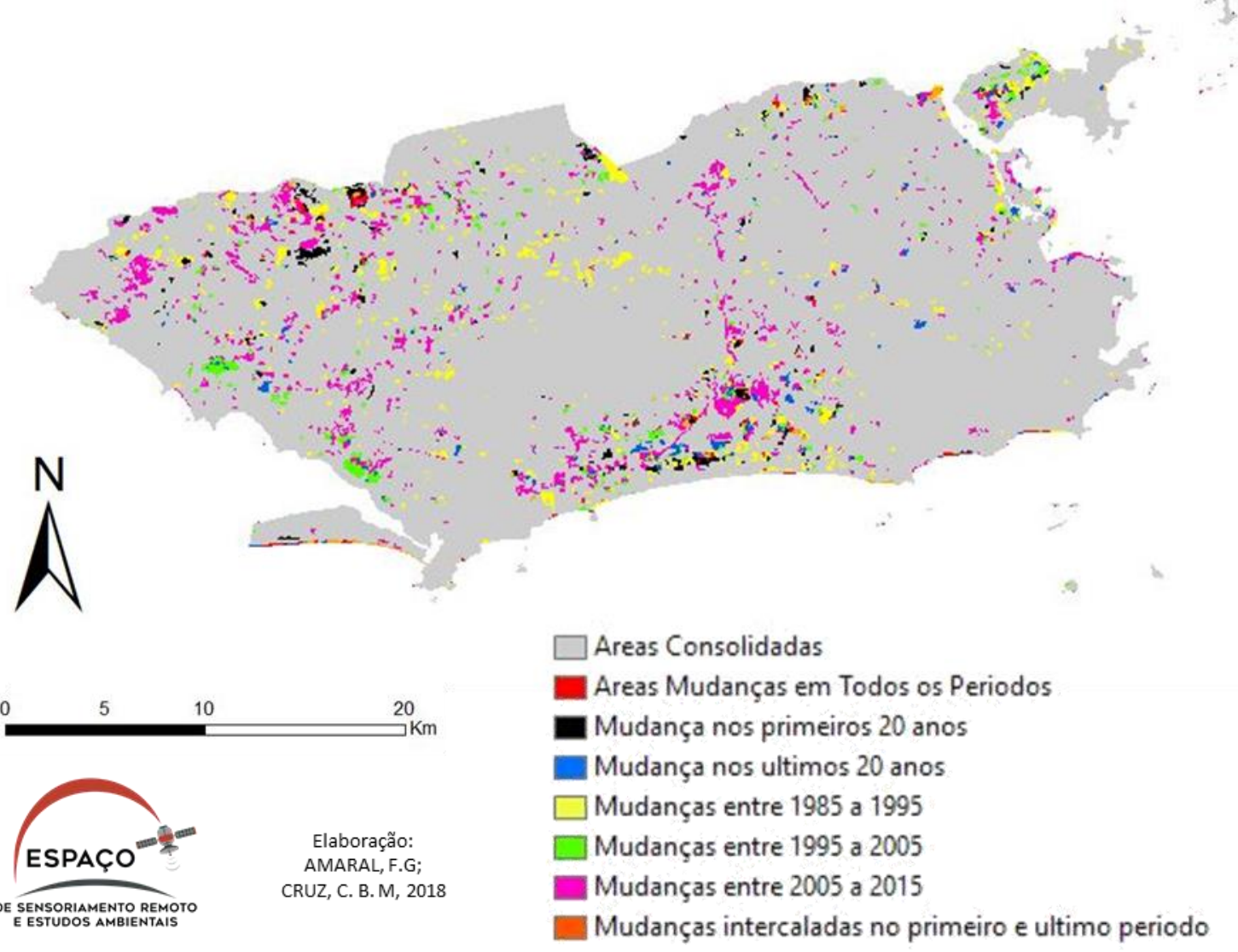

Figura 17 - Dinâmica Espaço-Temporal do Município do Rio de Janeiro

\begin{tabular}{|c|c|c|c|c|c|}
\hline Classificação & AP1 & AP2 & AP3 & AP4 & AP5 \\
\hline Áreas Consolidadas & 26,7 & 90,7 & 157,7 & 230,1 & 443,9 \\
\hline Áreas Mudanças em Todos os Períodos & 0,2 & 0,3 & 1,6 & 2,9 & 3,1 \\
\hline Mudança nos primeiros 20 anos & 0,3 & 0,3 & 3,2 & 5,6 & 9,3 \\
\hline Mudança nos últimos 20 anos & 0,7 & 0,7 & 3,2 & 6,3 & 7,1 \\
\hline Mudanças entre 1985 a 1995 & 0,9 & 1,9 & 9,1 & 13,6 & 27,9 \\
\hline Mudanças entre 1995 a 2005 & 1,3 & 1,2 & 7,6 & 10,3 & 21,0 \\
\hline Mudanças entre 2005 a 2015 & 3,1 & 4,4 & 16,5 & 21,8 & 46,0 \\
\hline $\begin{array}{c}\text { Mudanças intercaladas no primeiro e } \\
\text { último período }\end{array}$ & 0,3 & 0,3 & 2,0 & 3,0 & 4,0 \\
\hline
\end{tabular}

Tabela 2 - Análise Quantitativa das Mudanças na Cobertura da Terra, em Área $\left(\mathrm{km}^{2}\right)$ e por APs

Como pudemos perceber no primeiro mapa de mudanças apresentado as áreas que mais possuem mudanças absolutas foi a AP5, devido a expansão urbana em 
diversos bairros dessa AP seguida pela AP4 devido aos grandes eventos que o município sediou principalmente no último período de estudo. Já na tabela relativa as áreas que nos dá a porcentagem de áreas de mudança percebemos que as AP3, AP4 e AP5 tiveram uma mesma porcentagem de mudanças se pegarmos todo o período de estudo e em todas as três áreas essas mudanças foram bem distribuídas durantes os períodos.

\begin{tabular}{|c|c|c|c|c|c|}
\hline Classificação & AP1 & AP2 & AP3 & AP4 & AP5 \\
\hline Áreas Consolidadas & 80,0 & 91,0 & 78,5 & 78,4 & 78,9 \\
\hline Áreas Mudanças em Todos os Períodos & 0,7 & 0,3 & 0,8 & 1,0 & 0,5 \\
\hline Mudança nos primeiros 20 anos & 0,8 & 0,3 & 1,6 & 1,9 & 1,7 \\
\hline Mudança nos últimos 20 anos & 2,0 & 0,7 & 1,6 & 2,1 & 1,3 \\
\hline Mudanças entre 1985 a 1995 & 2,6 & 1,9 & 4,5 & 4,6 & 5,0 \\
\hline Mudanças entre 1995 a 2005 & 3,9 & 1,2 & 3,8 & 3,5 & 3,7 \\
\hline Mudanças entre 2005 a 2015 & 9,2 & 4,4 & 8,2 & 7,4 & 8,2 \\
\hline $\begin{array}{c}\text { Mudanças intercaladas no primeiro e último } \\
\text { período }\end{array}$ & 0,9 & 0,3 & 1,0 & 1,0 & 0,7 \\
\hline
\end{tabular}

Tabela 3 - Análise Quantitativa das Mudanças em Porcentagem por APs do Município

Para exemplificar melhor essas dinâmicas foram escolhidas cinco recortes dentro do município para a localização das mudanças e entendimento do método, todos apresentados na Figura 18.

O primeiro recorte é a zona da Barra onde hoje encontramos a Terminal Recreio dos BRTs TrasOlímpica e TrasOeste (Figura 6 e 7). Essa área possui uma dinâmica interessante pois possui mudanças na paisagem em todos os períodos de estudo. Os primeiros períodos são devido a urbanização da Barra da Tijuca e sua consolidação como uma zona de alta densidade, o último período é devido as dinâmicas sofridas para a realização dos grandes eventos que aconteceram do Rio entre 2007 a 2016, sendo eles os Jogos Pan-americanos de 2007, a Copa do Mundo de 2014 e os Jogos Olímpicos e Verão de 2016. Nessas imagens podemos ver as mudanças causadas pelo BRT, e os mais novos empreendimentos em rosa. As outras cores mostram mudanças anteriores, como os condomínios mais antigos. Outra coisa que podemos observar é a consolidação da área das lagoas mais próximas ao mar, elas estão em cinza.

O segundo recorte é da Ilha do Fundão, que sofreu bastante com dinâmicas na sua paisagem também devido as novas instalações e a modernização da Universidade Federal do Rio de Janeiro nos últimos 30 anos. Nesse segundo recorte podemos observar as grandes mudanças na área da Maré no final dos anos 80 e início dos 90 e as mudanças na Cidade Universitária que ocorreram em todos os períodos. Destaca-se e a instalação do CENPES 2.

O terceiro recorte é a área do Porto do Rio de Janeiro, essa área sofreu uma grande mudança nos últimos 3 anos devido a criação do projeto Porto Maravilha pela Prefeitura do Rio. Nessas imagens da Área Central da cidade podemos observar que a principal mudança foi a Revitalização da Área Portuária, com a demolição da Perimetral e da Construção da Novas Vias de Acesso ao Centro. Por isso maior parte das mudanças aparece em rosa. Mas além delas podemos ver a área onde hoje está instala a cidade do Samba, nela houve dinâmicas anteriores também como a própria criação da cidade do Samba.

O quarto recorte é de uma área da Zona Norte da cidade, com bairros da Grande Madureira, podemos observar que essa área é bem consolidada, mas nos últimos anos 
houve mudanças na infraestrutura da região como a construção do Parque Madureira. As imagens acima mostram muito claramente em rosa a grande mudança que o Parque Madureira trouxe na paisagem. Fora isso poucas mudanças pulverizadas na área e principalmente no último período de análise.

O último recorte escolhido foi novamente uma área da Barra/Jacarepaguá, onde hoje é o Parque Olímpico da Barra, essa área é bem complexa pois possui mudanças. Essas mudanças apresentadas nas figuras anteriores da área do Parque Olímpico e dos Condomínios da Av. Abelardo Bueno. Podemos observar que essa área possui uma dinâmica do espaço em todos os períodos. Podemos observar o Pq. Olímpico como uma mudança nos últimos anos, e a construção do novo empreendimento ao lado ao norte. Além disso algumas mudanças mais antigas na base do maciço da Pedra Branca.
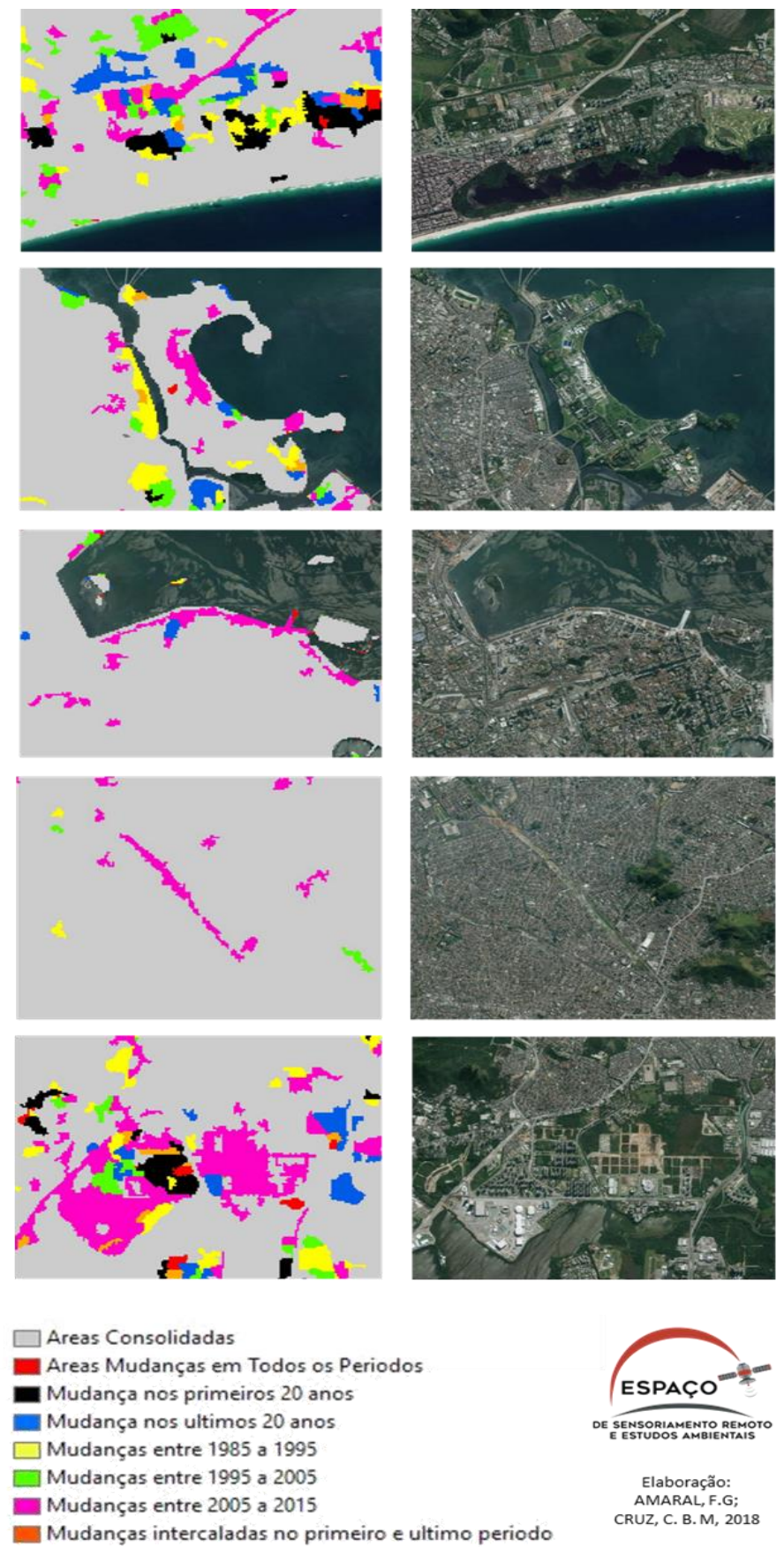

Figura 18 - Recortes de áreas de Mudança do município do Rio de Janeiro 


\section{Conclusão}

Ao fim desse artigo pode-se dizer que os objetivos foram alcançados, mesmo que com processos desgastantes, um mapa de mudanças foi obtido e junto a ele uma metodologia de detecção de mudanças e de análise espaço-temporal foi construída.

O trabalho se apropria do Sensoriamento Remoto e da Análise Espacial como materiais e métodos relevantes ao entendimento da dinâmica de uma paisagem complexa como a da cidade do Rio de Janeiro. Experiências como esta, trazem informações espaço temporais muito significativas e que podem ser aplicadas a diferentes objetivos e análises.

Levando em consideração os resultados, fica-se claro que tanto o préprocessamento, tanto as análises exploratórias dos descritores podem ser aprimoradas e otimizadas, para a obtenção de melhores resultados de forma ainda menos trabalhosa e com maior rapidez, mas de certa forma os dois métodos utilizados nessa metodologia foram bem satisfatórios e corresponderam bem as expectativas esperadas para um trabalho de caráter de exploração.

O pré-processamento de imagens é muito importante quando falamos de estudos multitemporais e os resultados deixam isso bem claro. Sem esse pré-processamento as análises feitas podem ser incoerentes devido a problemas geométricos e radiométricos nas imagens.

No âmbito da geometria conclui-se que as imagens vindas da USGS são bem ortorretificadas na área de estudo e que não é necessária a realização de novas correções geométricas mais avançadas para estudos multitemporais entre os sensores TM e OLI, o que diminui a carga do pré-processamento para análises de média resolução. Isso faz a série Landsat um aliado muito importante em estudos temporais muito extensos.

No âmbito radiométrico, as imagens ainda necessitam de bastante cuidados antes de passarmos para o PDI propriamente dito, mas que depois de todas as etapas as imagens se tornam quase que perfeitas para análises multitemporais, mas que essas etapas ainda requerem tempo de processamento. Os resultados obtidos foram considerados promissores, embora ainda haja necessidade de aprofundar mais nas etapas desse pré-processamento radiométrico.

Já a segunda metade da metodologia temos que considerar que mesmo de forma trabalhosa os resultados obtidos foram muito satisfatórios e surpreendentes, principalmente em relação aos descritores dinâmicos e seus resultados. O método com o uso das amplitudes de bandas espectrais e de índices radiométricos em todas as fases da classificação, segmentação e modelagem foram muito importantes para a obtenção desses resultados. A análise exploratória dos descritores dinâmicos foi um ótimo método de busca das melhores formas de classificação e nos deu caminhos para melhorar ainda mais os resultados do mapeamento.

Vale salientar ainda que os processos usados nesse artigo foram especificamente para uma única área e a replicabilidade e responderam satisfatoriamente para esse recorte espacial e para esse recorte temporal, e outras pesquisas necessitam ser realizadas para testes de replicação dessa metodologia, para necessidades temporais, espaciais e até escalares diferentes.

Por fim o mapa de mudança produzido pode ajudar no entendimento da dinâmica urbana do município e sua área de entorno, contribuindo para tomadas de decisão estratégicas para a área de estudo e ainda que a partir da metodologia aplicada de álgebra de imagens, e com a aplicação de métodos de análise espacial, foi possível entender a dinâmica do espaço do município do Rio de Janeiro a partir das mudanças espectrais das imagens. Os resultados foram bem satisfatórios vide que a maior parte 
das mudanças conhecidas foram bem representadas no mapa criado.

\section{Bibliografia}

ABREU, Marcelo Bueno. Contribuição metodológica para detecção de mudança em cobertura florestal em mesoescala. Tese (doutorado) - Geografia, UFRJ. 2018

AMARAL, F. G. Análise Exploratória de Descritores Dinâmicos Orbitais para Estudos Multitemporais. Trabalho de Conclusão de Curso. Bacharelado em Ciências Matemáticas e da Terra - Sensoriamento Remoto e Geoprocessamento, UFRJ, 2017.

AMARAL, F. G. Detecção de Mudanças no Município do Rio de Janeiro: A Situação das Unidades de Conservação dos Maciços Costeiros. Trabalho de Conclusão de Curso. Bacharelado em Ciências Matemáticas e da Terra - Patrimônio Natural e Ciências da Terra, UFRJ, 2017.

BATISTA, Marlos Henrique. Classificação hierárquica orientada a objeto em imagens de alta resolução espacial empregando atributos espaciais e espectrais, Dissertação de Mestrado - Sensoriamento Remoto. UFRS, 2006.

BRUZZONE, Lorenzo; COSSU, Roberto. An adaptive approach to reducing registration noise effects in unsupervised change detection. IEEE Transactions on Geoscience and Remote Sensing, v. 41, n. 11, p. 2455-2465, 2003.

CANTY, Morton J., Allan A. Nielsen, and Michael Schmidt. "Automatic radiometric normalization of multitemporal satellite imagery." Remote Sensing of Environment, 2004

COPPIN, Pol et al. Review Article Digital change detection methods in ecosystem monitoring: a review. International journal of remote sensing, v. 25, n. 9, p. 15651596, 2004.

CRUZ, Carla B. M. et al. Mapping the Atlantic Forest: GEOBIA contributions in a multiscale approach. In: GEOBIA 2018 - GEOBIA IN A CHANGING WORLD, 2018

ESCOBAR, Nadia Romina Cardozo. Normalização radiométrica para detecção de mudanças da cobertura da terra em IBAs situadas no Departamento Boquerón, Paraguai. In: Simpósio Brasileiro de Sensoriamento Remoto - SBSR, XVII., 2015, João Pessoa-PB, Brasil. Anais... [S.1.]: INPE, 2015.

EXPLORER, USGS Earth. Disponível em $<$ http://earthexplorer. usgs. gov/>. Acesso em, v. 10, 2017.

FERNANDES, Pedro José Farias et al. Modelo Automático de Normalização Radiométrica de Série Multitemporal Landsat-5 Usando Pontos Pseudoinvariantes (PIF). Revista Brasileira de Cartografia, v. 69, n. 2, 2017.

FLORENZANO, Teresa Gallotti. Geotecnologias na geografia aplicada: difusão e acesso. Revista do Departamento de Geografia, v. 17, p. 24-29, 2005. 
GÜRTLER, Salete, et al. Planilha eletrônica para o cálculo da reflectância em imagens TM e ETM+ Landsat. Revista Brasileira de Cartografia, 2005

HAY, Geoffrey J.; CASTILLA, Guillermo. Geographic Object-Based Image Analysis (GEOBIA): A new name for a new discipline. In: Object-based image analysis. Springer, Berlin, Heidelberg, 2008. p. 75-89.

LANG, S.; BLASCHKE, T. Análise da paisagem com SIG. 1a. ed. São Paulo: Oficina de Textos, 2009. 424p.

LU, Dengsheng et al. Change detection techniques. International journal of remote sensing, v. 25, n. 12, p. 2365-2401, 2004.

MALUF et al. Eficácia de um método de normalização radiométrica utilizando imagens Landsat 5 TM. In: XVII Anais Simpósio Brasileiro de Sensoriamento Remoto - SBSR, 2015, João Pessoa-PB, Brasil. INPE, 2015.

MENESES, Paulo Roberto et al. Introdução ao processamento de imagens de sensoriamento remoto. Brasília: UnB, p. 01-33, 2012.

NOVO, Evelyn M.L. de Moraes. Sensoriamento Remoto. Princípios e Aplicações, v. 4, 2008.

NOVO, Evelyn M.L. de Moraes. Sensoriamento Remoto. Princípios e Aplicações. Editora Edgard Blücher, 1989

PAOLINI, Leonardo, et al. Radiometric correction effects in Landsat multi-date/multi-sensor change detection studies. International Journal of Remote Sensing, 2006

ROSA, Roberto. Geotecnologias na geografia aplicada. Revista do Departamento de Geografia, v. 16, p. 81-90, 2011.

SANTOS, Rozely F dos. Planejamento ambiental: teoria e prática. 184p. Oficina de Textos, São Paulo, SP, Brasil. ISBN, v. 355771044, 2004

SHALABY, Adel, and TATEISHI, Ryutaro. Remote sensing and GIS for mapping and monitoring land cover and land-use changes in the Northwestern coastal zone of Egypt. Applied Geography, 2007

SILVA, Julia Q. L. Detecção de mudança em áreas antrópicas no município do Rio de Janeiro nos anos de 1990, 2004 e 2014 auxílio da temperatura de superfície. Dissertação (mestrado) - Universidade Federal do Rio de Janeiro, Instituto de Geociências, Departamento de Geografia, Programa de Pós-Graduação em Geografia, 2016.

SINGH, Ashbindu. Review article digital change detection techniques using remotelysensed data. International journal of remote sensing, v. 10, n. 6, p. 989-1003, 1989. 
VICENS, R.S et al. Método híbrido de detecção de mudanças: uma associação entre classificação baseada em objetos e baseada em pixels. Revista Brasileira de Cartografia, 68 (05), p. 883- 899, 2016

YANG, Xiajun, and C. P. Lo. Relative radiometric normalization performance for change detection from multi-date satellite images. Photogrammetric Engineering and Remote Sensing, 2000

YUAN, Ding, and Christopher D. Elvidge. Comparison of relative radiometric normalization techniques. ISPRS Journal of Photogrammetry and Remote Sensing, 1996

WECKMÜLLER, Rômulo; VICENS, Raúl Sánchez. As geotecnologias e a detecção de trajetórias evolutivas da paisagem: possibilidades metodológicas e aplicações. Revista Brasileira de Geografia Física, v. 11, n. 06, p. 2140-2159, 2018. 